\title{
The Emerging Global Campus Model
}

\author{
Roumen Nikolov
}

\begin{abstract}
This paper analyses the Emerging Global Model of universities as well as the changes which the ICT drives in a global scale. The emergence of e-Infrastructure for e-Science, the Open Educational Resources movement, e-Libraries and the tendency of building global educational alliances are analysed as well. The paper puts in focus the influence of the Web 2.0 technologies and the new organizational models they drive, e.g. Enterprise 2.0, University 2.0. A new university model is defined - the Emerging Global Campus Model. Some arguments that the ultimate result of the ICT driven transformation in the world could make the whole world to become a Global Campus in the next few decades.
\end{abstract}

Key words: Emerging Global Model, Emerging Global Campus Model, e-learning, e-infrastructure, open educational resources, e-book, e-library, Web 2.0, University 2.0, virtual organizations

\section{THE EMERGING GLOBAL MODEL}

In the knowledge intensive society, research universities, which are key institutions for social and economic development, are becoming more international. A subset of research universities reflects a new phenomenon, defined as the Emerging Global Model (EGM) of the 21st century research university [13]. The emphasis is on the international nature of a group of institutions that embrace of the forces of globalization. The EGM universities are characterized by an intensity of research that far exceeds past experience. They are engaged in worldwide competition for students, faculty, staff, and funding and they operate in an environment in which traditional political, linguistic, and access boundaries are increasingly loosing their traditional roles. Universities in economically developed and developing nations encourage students to participate in short-term study abroad programs, e.g. the European mobility programs are seeking to create a sense of transnational Europeanness [31], which is probably the most extensive international mobility of students. The heart of the EGM is an expansion of the older functions of teaching, research and service into an organization that can be described as a knowledge conglomerate [6].

\section{GLOBAL ALLIANCES}

One could observe a clear tendency in building global educational alliances. There are a variety of reasons for forming partnerships or consortia of universities [9]: sharing resources, costs and infrastructure to deliver e-learning; competing with international providers; reducing duplication among existing universities. One of the first global university networks is Universitas $\mathbf{2 1}$ which includes 21 leading research-intensive universities in thirteen countries (http://www.universitas21.com). Collectively, its members enrol over 650,000 students, employ over 130,000 staff and have over 2 million alumni. Their collective budgets amount to over US\$13bn with an annual research grant income of over US\$3bn. All member institutions are research-led, comprehensive universities providing a strong quality assurance framework to the network's activities. They offer opportunities for global education, research, projects and services.

Publishing companies are also active in building alliances with universities and other educational service providers [12]. The global publishers Pearsons and Thompson Learning are market leaders in the field. Several years ago Pearsons initiated partnerships with some traditional universities in the UK and the USA and they have extended their alliances so that they can offer a wider range of learning services. For example, in partnership with America Online, Pearsons has commenced its "Learning Network" with the University of Phoenix which got the rights to provide customized electronic content based on Pearsons' textbooks. In 2000 Thompson invested in Universitadas 21. The publishers could use their core skills in marketing, distribution, content and electronic 
delivery systems and in alliance with universities they can offer new products and services to existing and new markets.

\section{OPEN EDUCATIONAL RESOURCES}

The global education movement gave rise of another movement - Open Educational Resources (OER), which demonstrates great potential to overcome demographic, economic, and geographic educational boundaries and to promote life-long learning and personalized learning. The most often used definition of OER is "digitized materials offered freely and openly for educators, students and self-learners to use and reuse for teaching, learning and research" [21]. There are three areas of open educational resources: learning content, tools and implementation resources (mostly - intellectual property licenses). Some of the most popular initiatives are:

- MIT OpenCourseWare (http://ocw.mit.edu) - they published on the Web about 1,800 courses which are made available to educators and learners worldwide at no cost. Some evaluation of the MIT OCW showed that the web site was visited more than 8.5 million in 2005, a 56\% annual increase from 2004;

- OpenCourseWare Consortium (http://www.ocwconsortium.org/) - a collaboration of more than 100 higher education institutions and associated organisations from around the world creating open educational content using a shared model.

A special case of OER are the open textbooks [5]. The open textbooks, as well as the OER movement, are very important instruments to approach the educational gap in the developing countries. New tools for e-books are also being developed [8]. Some recent OER developments are related to building open repository of research publications and other research outputs, e.g. - Dspace at MIT (http://dspace.mit.edu/), DSpace of the TENCompetence project (http://dspace.ou.nl/), TeLearn of the EU Kaleidoscope network of excellence (http://telearn.noe-kaleidoscope.org/), etc. The DSpace at MIT Thesis Collection, for instance, contains more than 20000 items.

\section{E-INFRASTRUCTURE FOR E-SCIENCE}

The term e-infrastructure refers to a new research environment in which all researchers - whether working in the context of their home institutions or in national or multinational scientific initiatives - have shared access to unique or distributed scientific facilities (including data, instruments, computing and communications), regardless of their type and location in the world (http://cordis.europa.eu/). The einfrastructure (cyberinfrastructure) is a combination of hardware, software, services, personnel and organization, which provides a wide range of services for the global research communities [2]. It should enable research communities and projects to rely on an effective application-specific, but interoperable, knowledge environments for research and education. Interoperability is important for facilitating multidisciplinary projects as the evolution of research dictates.

Increasingly, new types of scientific organizations and supporting environments for science based on research communities are emerging, e.g "laboratories without walls" [2]. They can serve individuals, teams and organizations in ways that revolutionize the research practice. The industry could be an important partner in development and deployment of e-infrastructure, but it could also benefit from it. The e-infrastructure could be a platform for co-investments and building new partnerships between universities and industry and thus - catalyze new organizational forms for knowledge creation and education in the digital age [2]. Organizations of the type are: the Enabling Grids for EsciencE - EGEE (http://public.eu-egee.org/) and nanoHUB.org (http://nanohub.org/). The model of Global Research Library (GRL) is also emerging. The fast development of the Web 2.0 technologies, the OER and the e-infrastructure are driving changes in the library model as well. Libraries will be catalysts for facilitating knowledge-sharing. The European digital library Europeana (http://www.europeana.eu) contains more than 4 million digital items: images, texts, sounds and videos. 


\section{THE EMERGING GLOBAL CAMPUS MODEL}

The EGM should be projected on the new global ICT environment related to the OER movement, e-infrastructure and virtual organizations developments. The characteristics of the Emerging Global Campus Model (EGCM) could be considered as an extension of the ones of the EGM. We will adopt the assumption that the "current educational reform is driven by three major factors - asynchronous space and time, responsive environments, and virtual reconstruction" [11] and will consider Virtual Campus as a virtual reconstruction of the existing campuses and "bricks and mortal" buildings. This means to "redesign and reconfigure the human experience of existing physical spaces without having to make physical, structural changes in buildings" [11]. Thus, virtual spaces would complement the physical spaces when designing an effective, student centered, learning environment [19]. The virtual campus will not only integrate a variety of software tools but also integrate all the physical tools that can be found in physical campus. We adopt also that the concept of learning spaces as one of the main features of the future learning [24]. Place-making is a very appropriate metaphor for designing cyberspace since "the virtual places will include socio-cultural and perceptual qualities, enriching them to the point where they may approach - perhaps even surpass - comparable physical settings" [7]. In such way even non-campus universities could build their virtual campuses and make the campus education not only a good American tradition [29] but rather a world standard for global higher education. Refering to this tradition, an "Educating by Design" principle [26] could be applied by transforming it to the virtual campus design issues. The institutional virtual campus could evolve into a global virtual campus comprising all university branches and partner institutions. The virtual campus should be opened towards the other stakeholders and the users and provide virtual places where they could meet, cooperate, communicate, share information and knowledge.

One of the measures for global reach of a university is the percentage of foreign students, PhDs and postdocs. The EGM universities give special attention to international PhD students, seeking the best minds worldwide to contribute to the research agenda as part of their doctoral studies [13]. In realation to the Bologna Process and Lisbon Strategy and the targeted "Europenness" [31], the EGCM might serve for defining different virtual mobility schemes by following the Virtual Erasmus model, which complements the existing Erasmus exchange programmes [22]. The Virtual Erasmus can be used to prepare and follow-up the physical mobility or/and take courses at the home university while staying abroad. In addition, it embeds "networked e-learning (in transnational collaboration of teachers and students) as an integrated part in mainstream higher education, aiming at transferability, scalability and sustainability: joint programme and course development, joint learning activities as virtual integrated elements of blended learning, 'following' (e.g. elective) courses abroad in a virtual mode" [22]. Similar combined virtual/physical mobility model could be applied for mobility of researchers and for "crosssector" (academia-industry) mobility schemes. These models could be further extended towards a combined Virtual/Physical Recrutement Model since the EGM (respectively EGCM) universities are "adopting worldwide recruitment strategies fo students, faculty, and administrators" [13]. The model of virtual mobility would be very useful for developing countries in their efforts to reduce the brain-drain and turn it into a brain-gain status and thus helping to reduce the rising "knowledge gap" between them and the developed countries. In order to fulfill this mission, the EGCM universities should closely cooperate with international non-governmental organizations and multi-governmental organizations, such as UNESCO, World Bank and OECD.

Similarly to the knowledge intensive companies, the need of an effective knowledge management strategy is becoming one of the main characteristics of an EGCM university as well. Knowledge Management (KM) emerged as a result of the development of ICT and the changes in the organizations' structure, functions and management 
practices all over the world. The globalization of educational markets and the global competition put the focus on effective management of intangible assets as a way universities to achieve competitive advantages since the knowledge is the essential asset of them. We adopt the framework "The KM Spectrum" [3] as a classification scheme of the KM activities: Transactional KM, Analytical KM, Asset Management KM, Processbased KM, Developmental KM, Innovation/creation KM. An EGCM university should apply KM tools for: generation of knowledge; storing, codification and representation of knowledge; knowledge transformation and knowledge use; transfer, sharing, retrieval, access and searching of knowledge. Such university should also implement a knowledge management strategy based on a (Web 2.0) KM system with a distributed architecture [1].

In order to become an "enterprise like" organization the universities tend to adopt ICT not only for e-learning, but also for management and administrative purposes, i.e. to implement ERP systems along with change management and e-learning [17]. However the fast developments of the Web 2.0 technologies and socials software networks are causing dramatic change in the society [23]. Gardner states: "Although Web 2.0 is now entering the Trough of Disillusionment, it will emerge within two years to have transformational impact, as companies steadily gain more experience and success with both the technologies and the cultural implications" (http://www.gartner.com). The Web 2.0 technologies influence the business world and the notion Enterprise 2.0 has been introduced [10]. McAfee gave the most cited definition: "Enterprise 2.0 is the use of emergent social software platforms within companies, or between companies and their partners or customers" [10, 27, 28]. The Enterprise 2.0 model provides opportunities for company improvements in the area of innovation, collaboration, knowledge sharing, using collective intelligence and searching and discovering. This model is gradually adopted not only by many small companies, but also by a large number of big companies as well, such as IBM, Oracle and BT.

The industrial economy knowledge monopolies are breaking down and the innovation is becoming more collaborative, distributed and open [27]. The Web 2.0 technologies give rise to company's business and innovation webs. Tapscott states that "in most industries, innovation increasingly depends on dense networks of public and private actors and large pools of intellectual property that routinely combine to create end products". Tapskott and Williams put in the focus the opportunities for the new mass collaboration model to change "how companies and societies harness knowledge and capability to innovate and create value" [28]. The so called "ideagoras" emerged, i.e. Web 2.0 based environments where researchers and developers can collaboratively develop innovations. Companies are innovation seekers when they face some difficult problems, and they could globally challenge the experts - the innovation providers [14]. An independent innovation platform could also enhance the organizational innovation processes and thus contribute to better exploitation and use of the organizational knowledge management portals by improving the innovation and knowledge management processes within the organization [1].

As it was stated above, the Web 2.0 technologies and tools provide new avenues for cooperation between university and industry in the areas of training, research and innovation, which is a solid ground for joint ICT professional competency development. On the way to a knowledge society in a dynamic ICT environment the universities should catalyse a process of deep institutional change. As Unsworth states, one of the major challenges facing the universities in the next decade is to reinvent themselves as information organizations [30]. He emphasizes that the "universities are, at their core, organizations that cultivate knowledge, seeking both to create knowledge and to preserve and convey knowledge, but they are remarkably inefficient and therefore ineffective in the way that they leverage their own information resources to advance that core activity". The model of University $\mathbf{2 . 0}$ naturally emerged as a framework for universities to adapt to the social computing phenomena and to the networked information economy. We define University 2.0 as a "research and entrepreneurial university which integrates Web 2.0 
technologies and applications in all university activities, including ones with all knowledge intensive stakeholders, and implements the features of the Enterprise 2.0" [15]. The Web 2.0 based virtual learning environments provide opportunities for students, professors, companies and other stakeholders to cooperate in a $24 / 7$ fashion [15, 18]. The virtual space of a University 2.0 is a natural place, where the two worlds - the academic and the corporate ones, could establish solid bridges and naturally integrate, especially if the university adopts most of the principles of the Entreprise 2.0 model $[15,16]$.

An EGCM university should also become a virtual organization. Virtual Organizations (VOs) are a fast-growing phenomenon in all work settings. A VO is "a group of individuals whose members and resources may be dispersed geographically and institutionally, yet who function as a coherent unit through the use of e-infrastructure" [20]. A VO is typically enabled by, and provides shared and often real-time access to, centralized or distributed resources, such as specific tools, applications, data, and sensors, and experimental operations. The term VO can encompass systems known by other names such as eScience or e-Research, distributed workgroups or virtual teams, virtual environments, and online communities. VOs include a broad range of operational options, e.g they can be formal or informal, planned or unplanned, transient or long lived. Most VOs, however, share several common characteristics [20]: distributed across space, distributed across time, dynamic structures and processes, computationally enabled and computationally enhanced (with simulations, databases, and analytic services). Such organizations are EGEE and nanoHUB.org. VOs are enabling new form of learning: learning through interactive visualizations and simulations [20]. The cyber-services also demand a new level of technical competence from the workforce and citizens [20].

\section{CONCLUSIONS}

The technologies are ever changing and the new generations of Web are on the horizon - Web 3.0, Web 4.0, etc. They are related to increasing the intelligence of the Web. Davis describes these trends: "The semantic wave embraces four stages of internet growth. The first stage, Web 1.0, was about connecting information and getting on the net. Web 2.0 is about connecting people — putting the "I" in user interface, and the "we" into Webs of social participation. The next stage, Web 3.0, is starting now. It is about representing meanings, connecting knowledge, and putting these to work in ways that make our experience of internet more relevant, useful, and enjoyable. Web 4.0 will come later. It is about connecting intelligences in a ubiquitous Web where both people and things reason and communicate together." [4]. An emerging trend in the academic world is to integrate Web X.0 with the global e-infrastructure [25]. Having in mind the life-long learning need and the trend of integration of all existing forms of education, we might expect that the whole world would become a Global Campus in the next few decades.

\section{REFERENCES}

[1] Antonova, A., Nikolov, R. (2008), Modelling Concept Design of Innovation Platform: Knowledge Management Approach, KMO2008, Finland, pp. 283-294

[2] Atkins, D. et al (2003), Revolutionizing Science and Engineering Through Cyberinfrastructure, Report of the NSF Panel on Cyberinfrastructure, NSF, January

[3] Binney D. (2001), The knowledge management spectrum - understanding the KM landscape, Journal of Knowledge Management, 5, 1, 33-42.

[4] Davis D. (2008), Project10X's Semantic Wave 2008 Report: Industry Roadmap to Web 3.0 \& Multibillion Dollar Market Opportunities, October

[5] Frydenberg, J., Matkin, G. (2007), Open Textbooks: Why? What? How? When?, University of California, Irvine, Distance Learning Center, Hewlett Foundation

[6] Geiger, R. (2004) Knowledge and Money: Research Universities and the Paradox of the Marketplace, Stanford, CA: Stanford University Press.

[7] Kalay, Y. (2004) Virtual learning environments, ITcon Vol. 9, Special Issue ICT Supported Learning in Architecture and Civil Engineering , pp. 195-207 
[8] Koychev, I., Nikolov, R., Dicheva, D. (2009a), SmartBook - a vision for the future e-book, $10^{\text {th }}$ IFIP Working Conference on Virtual Enterprises, Thessaloniki, Greece, Oct.

[9] Mason, R. (2006), The university - current challenges and opportunities, in: D'Antoni, S. (2006), The Virtual University. Models and Messages, UNESCO-IIEP

[10] McAfee, A.(2006), Enterprise 2.0: The Dawn of Emergent Collaboration, Sloan Management Review, Spring 2006, Vol. 47, No. 3, pp. 21-28

[11] McClintock, R. (1992), Power and Pedagogy: Transforming Education through Information Technology, Institute of Learning Technologies, New York

[12] Middlehurst, R. (2006), A world of borderless higher education - impact and implications, in: D'Antoni, S. (2006), The Virtual University, UNESCO-IIEP

[13] Mohrman, K., Ma, W., Baker, D. (2008), The Research University in Transition: The Emerging Global Model, Higher Education Policy, 2008, 21, (5-27)

[14] Nambisan S, Sawhney M. (2008), The Global Brain, Roadmap for Innovating Faster and Smarter in a Networked World, Pearson Education, New Jersey

[15] Nikolov, R. (2009), Towards University 2.0: A Space where Academic Education Meets Corporate Training, IPROF-09, Arnhem, The Netherlands, February 12 -15

[16] Nikolov, R.(2008a), A Model for European e-Competence Framework Development in a University Environment, International Workshop, October, Bulgaria.

[17] Nikolov, R. (2008b). From eLearning to eUniversity, ACM International Conference Proceeding Series; Vol. 374, Proceedings of the 9th International Conference on Computer Systems and Technologies, Gabrovo, Bulgaria, June 12 - 13

[18] Nikolov, R. (2007), Towards Web 2.0 Schools: Rethinking the Teachers Professional Development, in: Benzie, D.; Iding, M. (eds.): Proceedings of IFIPConference on "Informatics, Mathematics and ICT: A golden triangle", June 27-29, Boston

[19] Nikolov, R., Nikolova, I.(1996), A Virtual Environment for Distance Education and Training, IFIP WG3.6 Conference, Vienna, 2-4 September

[20] NSF (2007), Cyberinfrastructure Vision for 21st Century Discovery, National Science Foundation, Cyberinfrastructure Council, March

[21] OECD (2007), Giving Knowledge for Free: the Emergence of Open Educational Resources, OECD CERI

[22] Op De Beeck, I. (2005), REVE - Real Virtual Erasmus, EuroPACE, February

[23] O'Reilly, T (2005), What Is Web 2.0: Design Patterns and Business Models for the Next Generation of Software, O'Reily Net

[24] Punie, Y. \& Cabrera, M. (2006). The Future of ICT and Learning in the Knowledge Society, Report on a Joint DG JRC-DG EAC Workshop held in Seville, Oct.

[25] Reid, R., Edwards, P. (2009), ourSpaces - A Social Semantic Web Environment for eScience, Proceedings of the AAAI2009.

[26] Strange, C., Banning, J. (2001), Educating by Design: Creating Campus Learning Environments that work (1st ed.). San Francisco, CA: Jossey-Bass.

[27] Tapscott, D. (2006), Winning with the Enterprise 2.0, NPL Corporation

[28] Tapscott, D., Williams, A. (2006), Wikinomics. How Mass Collaboration Changes Everything, Penguin Group (USA), December

[29] Turner, P.(1995) Campus: An American Planning Tradition. MIT Press.

[30] Unsworth, J. (2008), University 2.0, in:R. Katz (2008), The Tower and the Cloud: Higher Education in the Age of Cloud Computing, pp. 227-237, Educause.

[31] Van Vught, F. (2007), Universities and the European Dimension, in: Enders, J., Vught, F. van (2007), Towards a cartography of higher education policy change. A Festschrift in Honour of Guy Neave, CHEPS, University of Twente

\section{ABOUT THE AUTHOR}

Assoc.Prof. Roumen Nikolov, PhD, Director of Centre of IST, FMI, Sofia University, Phone: +359 2 9713509, E-mail: roumen@fmi.uni-sofia.bg. 